\title{
Dynamic pricing and the peak electricity load problem
}

\author{
Paul Simshauser and David Downer* \\ AGL Energy Ltd \\ Level 6, 144 Edward Street \\ Brisbane, QLD 4001 \\ $\mathrm{Ph}+61730232491$
}

\begin{abstract}
Reforms to Australia's 45,000MW electricity market were met with remarkable success, but wholesale market gains have been largely exhausted. Above trend-growth investment in energy infrastructure is driving retail prices to levels that triggered the sectoral assault in the first place. This pressure should initiate the last piece of the reform puzzle - removing price regulation, installing smart meters and implementing dynamic pricing to halt the primary cause of the problem, rapidly rising peak demand. We find that such a change can lead to non-trivial reductions in household peak demand, with our sample load factor improving by 9 percentage points.
\end{abstract}

Keywords: Electricity Prices, Dynamic Pricing, Smart Meters.

JEL Codes: D61, L94, L11 and Q40.

\section{Introduction}

One of the most pronounced thematics associated with retail tariff levels in Australia's National Electricity Market (NEM ${ }^{1}$ ) has been the sudden change in trajectory. Taking the Queensland region as a typical example, with few exceptions electricity tariffs fell in real terms between 1955 and 2007. Over that 53-year period, tariff increases averaged just $68 \%$ of the change in the Consumer Price Index (CPI). A notable exception to this was between 1982 and 1986. Core inflation was running at about $8 \%$, while Queensland tariffs increased by about $12 \%$. This coincided with startling growth in the power system's capital stock, rising as it did from $\$ 7.0$ billion to $\$ 12.1$ billion (in 2011 dollars) in the space of just five years. ${ }^{2}$ This was driven by a $57 \%$ increase in generating and network plant capacity to $4,800 \mathrm{MW}$ (esaa, 1994). While the timing of events differed at the margins, similar patterns emerged in New South Wales (NSW), Victoria and South Australia. Once these 'build-out plans' were completed, a period of 'harvesting prior investments' ensued with real electricity tariffs reducing dramatically across Eastern Australia through to 2007.

At first glance, one could be forgiven for thinking we are once again in an exception period. Tariffs are now rising at multiples of the change in the CPI. Network capital expenditure (excluding generation) over the five-year period to 2015 in Queensland and NSW alone is forecast to exceed $\$ 31.5$ billion, compared to $\$ 7$ billion during 2001-2005. ${ }^{3}$ And generation plant capacity in the broader NEM has expanded by $21 \%$ to $44,800 \mathrm{MW}$ over the last five years. ${ }^{4}$

There are commonalities between the sharp run-up in the outlook for tariffs in the 1980s, and the 2010s. Both periods involved above-trend growth in the capital stock in response to rising demand and asset replacement. But key differences also exist. First, the 1980s investment cycle, undertaken in response to high energy demand forecasts, grossly exceeded actual requirements with the benefit of hindsight. As a result, tariff increases in subsequent periods decelerated below CPI as excess capacity was, over time, productively utilised. Second, the outlook for key

\footnotetext{
* Paul Simshauser is the Chief Economist at AGL Energy Ltd. He is also Professor of Finance at Griffith University's Business School. David Downer is a Pricing Analyst at AGL Energy Ltd. Correspondence should be directed to Paul Simshauser at psimshauser@agl.com.au. The views expressed in this article are those of the authors and not necessarily those of AGL Energy Ltd. ${ }^{1}$ For further information on the design and operation of Australia's National Electricity Market, see "An Introduction to Australia's National Electricity Market" (July 2010) which can be accessed at www.aemo.com.au/corporate/0000-0262.pdf

${ }^{2}$ Capital stock derived from esaa (1994) and inflation data from ABS.

${ }^{3}$ Simshauser, Nelson and Doan (2011 at p.86).

${ }^{4}$ esaa $(2005,2010)$ at Appendix I.
} 
commodity input costs (viz. fuel) was stable if not declining due to pronounced productivity gains in the mining sector. Third, expansion of the capital stock was accompanied by material technological enhancements including a shift to much larger, more fuel efficient and reliable turbogenerators. Structural enhancements also included greater network interconnection, and the addition of sizeable mining and manufacturing loads which in the event reduced the highly volatile household loads from $40 \%$ to $30 \%$ of aggregate demand. The new mining and manufacturing customers were desirable due to their flat and predictable load shape, enabling the electricity industry on the East Coast to expand the fleet of low-cost base load machines, thereby spreading the heavy fixed costs of the entire industry across greater units of output, thus producing a lower overall system average cost.

The outlook for the 2010s is different. Generation and network capacity additions do not appear to be grossly exceeding growth in peak energy demand, and so a harvest period seems unlikely. Inputs to the industry are experiencing heightened volatility; turbine prices, the cost of capital, labour construction costs, copper, steel, and above all, coal and gas. ${ }^{5}$ This latest expansion will also involve changes to the power generating technologies deployed, but in the main it will come at a cost penalty, driven by requisite environmental objectives and asset replacement. And finally, like the 1980s, peak demand has been demonstrably rising, but unlike the 1980, load growth is not structurally advantageous. New incremental load, increasingly driven by households and non-industrial enterprises, is extremely peaky, not the flat and predictable industrial loads of the 1980s.

In reviewing the factors present in the 2010s, for policy makers the obvious candidate capable of further microeconomic reform is the demand-side, and in particular peak demand. The perennial underperformer in most energy market reforms, demand-side participation represents an important frontier for policy makers because the principle means by which to do so, shifting from mechanical to digital metering, is now possible and economical due to reductions in smart metering costs (Faruqui and Sergici, 2010). Other factors impacting retail tariffs, outlined above, are simply the out-workings of properly functioning markets. Trivial 'demand response' in a rising cost environment, is not.

Household energy consumption in Australia, as with the United States, represents about $1 / 3$ of aggregate energy demand. But the contribution of household peak demand is entirely out-of-step. Since 2005, peak demand growth has been running at twice the growth rate of underlying energy demand (AEMC, 2011). This has been driven by rising disposable incomes, larger household floor space, and plunging appliance costs. That peak demand is rising so fast is hardly surprising given households are equipped with century old metering infrastructure which is unable to distinguish the time-of-use. Consequently, widespread time-of-use pricing has not been technically feasible. ${ }^{6}$ And ironically, where digital meters do exist such as in Victoria, time-of-use pricing as a default option is not yet politically feasible as this article later reveals. Either way, households currently have no incentive to adjust peak demand since the primary driver to do so is absent.

The purpose of this article is to analyse a subset of the gains associated with shifting to digital meters and dynamic pricing. This paper is structured as follows. In Section 2, an historical analysis of household electricity costs is presented. Section 3 illustrates the cost consequences of average pricing and declining load factors. Section 4 examines dominant thought on electricity demand. In Section 5, results from dynamic pricing pilots are presented. Section 6 then presents simulated modelling results of dynamic pricing to a sample of 3000 NEM customers equipped

\footnotetext{
${ }^{5}$ The coal and gas industries are increasingly seeking to export their commodities to the seaborne market, thus creating export priceparity pressure for domestic fuel users.

${ }^{6}$ Of course, separate metering, tariffs and ripple control exists for switchable hot water loads, but these loads are essentially controlled centrally, not by the customer.
} 
with digital meters. Section 7 considers policy implementation issues associated with dynamic pricing. Our concluding remarks follow.

\section{History of household electricity costs}

We have compiled 45 years of electricity price, consumption and payments data for residential customers in Queensland. This enabled us to generate an 'average annual household electricity bill' time series, represented by the stacked-bar series in Figure 1 and expressed in both nominal and real 2010 dollars. While not separately visible in Figure 1, consumption has increased from about 2MWh in 1966 to about 7.5MWh in 2010, and price has increased from about \$20/MWh in 1966 to $\$ 186 / \mathrm{MWh}$ in 2010. Accordingly, average household electricity costs have risen from $\$ 68$ per annum in 1966 to $\$ 1270$ by 2010 in nominal terms, or from about $\$ 700$ to $\$ 1270$ in real 2010 dollars. In Figure 1, we have also plotted a forecast electricity bill for the future year 2015 using pricing data from Simshauser, Nelson and Doan (2011a) with household incomes assumed to rise by $4.0 \%$ pa. Our forecast bill is $\$ 2,066^{7}$ in nominal terms, based on $7.5 \mathrm{MWh}$ and \$275/MWh.

The use of average weekly earnings data enables us to derive the relative proportion of household income represented by an electricity bill, depicted by the lines series. ${ }^{8}$ Our data indicates that in the 1960s, electricity bills represented $2.4 \%$ of household income before falling sharply in the early-1970s. The effects of the OPEC oil price shock led to rising electricity costs. And as noted earlier, this was heightened with the expansion of the power system between 1982 and 1986, peaking at $2.6 \%$ of income. The harvest period then followed with electricity costs falling to $1.7 \%$ of income through to 2007 . Our forecast for 2015 indicates that electricity will once again return to mid-1980's levels.

Figure 1: Average annual electricity bill vs. average weekly earnings

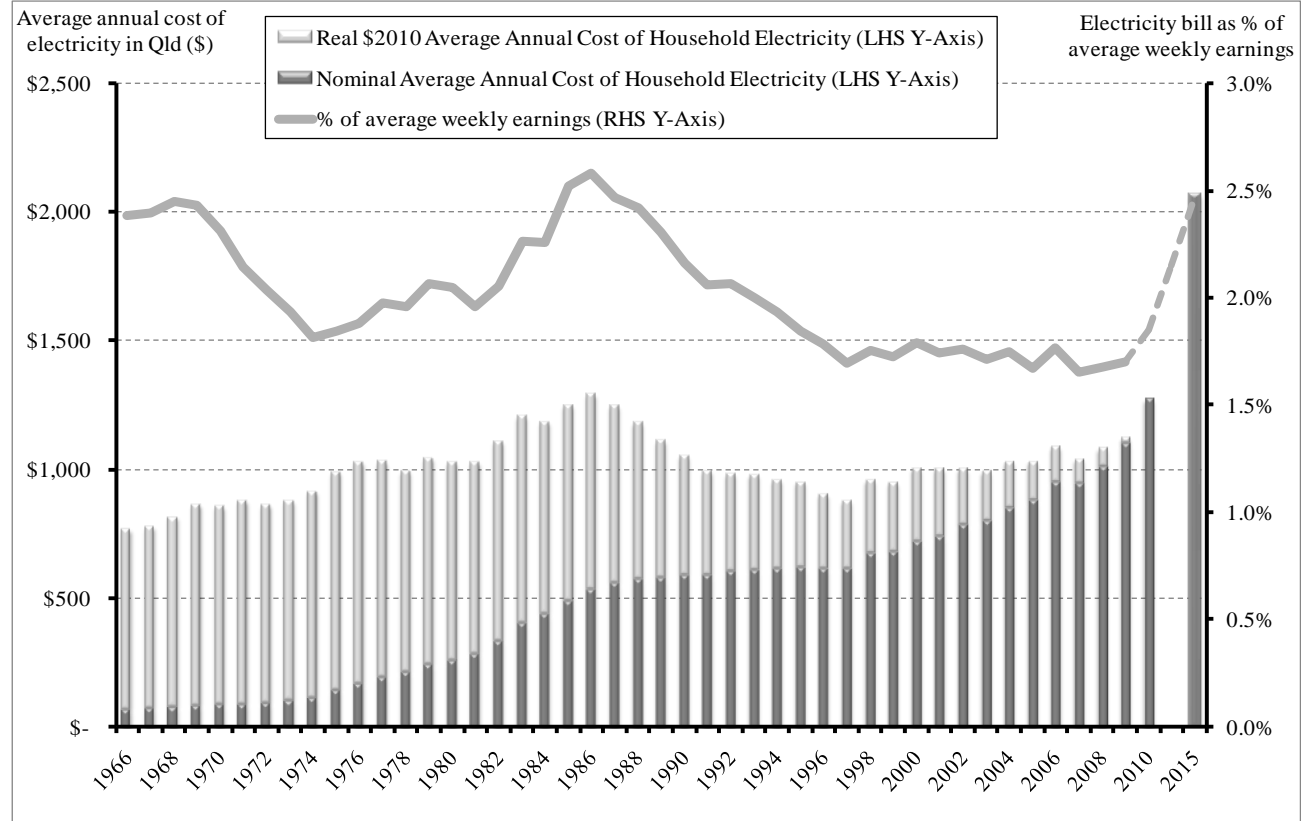

Source: esaa, ABS, AGL Energy Ltd.

Given the political economy of electricity tariffs, a sharp increase eventually invokes a policy response. Simshauser and Laochumnanvanit (2011) noted that the wholesale electricity market has been subjected to a comprehensive assault by policymakers, but the retail market remains

\footnotetext{
${ }^{7}$ This translates to about $\$ 1870$ in real 2010 dollars.

${ }^{8}$ Note that we have used 'full-time male' rates as representative of average weekly earnings because this series provided the longest trace, but this will overstates the average in relative terms.
} 
largely untapped. The areas which stand out are metering, metering services, demand response, and pricing structures.

\section{The cost and consequences of declining power system load factors}

When aggregate electricity demand is measured as a continuous half-hourly "load" throughout the year, the load factor can be determined as the ratio between maximum and average demand. A virtually flat consumption curve such as that typically associated with an aluminium smelter has a load factor close to unity. Conversely, highly 'peaky' household loads, as Figure 3 later reveals, typically have a load factor of $0.30-0.40$ in aggregate. Queensland's aggregate load factor across all sectors has historically been highly favourable at more than 0.70 (due to the predominance of the industrial and mining sectors) but over the past 5-6 years has fallen to 0.64. Conversely, South Australia's aggregate load factor is one of the worst in the OECD, at just 0.42 (esaa, 2011). We noted earlier that as system load factors approach unity, more low cost, base load plant can be added to the system which in turn greatly reduces the overall cost of supply and conversely, where peak demand rises faster than underlying energy (or base) demand, expensive peaking plant must be added with the cost being recovered across a diminishing level of throughput, thus heightening the overall cost of supply.

The notion of rapidly rising peak electricity demand has long been of interest to energy economists, dating back to the works of Electricité de France Chief Economist Marcel Boiteux (1949), and in an unrelated and virtually simultaneous study, Houthakker (1951), who was focused on Britain's power system. In post-World War II Europe, peak electricity demand was rising rapidly and opportunities for additional investment in electricity infrastructure were severely constrained given government priorities of dealing with post-war housing shortages and rearmament programs (Houthakker, 1951). Boiteux's (1949) seminal and much cited Peak Load Pricing article, first published in French (and later transcribed to English) noted that average rate tariffs were a key problem, which he described as follows:

\section{Figure 2: Optimum solution of electricity tariffs - average cost vs. peak and off-peak}

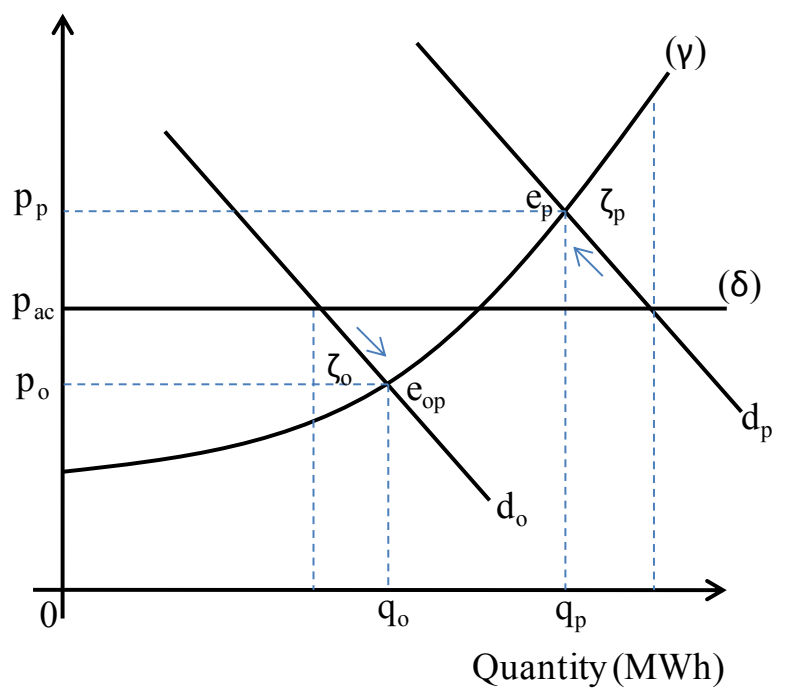

In Figure 2, the marginal running cost curve of the power station fleet is given by $(\gamma)$, while the line $(\delta)$ essentially equates to the averaged tariff, and usually a surrogate for industry average cost. Demand curves for peak and off-peak are represented by $d_{p}$ and $d_{o}$ respectively. When electricity is priced at average cost $\mathrm{p}_{\mathrm{ac}}$, excess consumption occurs in peak periods and an underutilisation of electricity equipment occurs during off-peak periods compared to equilibrium peak 
$e_{p}$ and off-peak $e_{o}$ - given time-of-use price and quantity combinations $\mathrm{p}_{\mathrm{p}}$ and $\mathrm{q}_{\mathrm{p}}, \mathrm{p}_{\mathrm{o}}$ and $\mathrm{q}_{\mathrm{o}}{ }^{9}$ The resulting efficiency losses arising from average cost pricing by comparison to time-of-use pricing are given by the two triangles $\zeta_{\mathrm{p}}$ and $\zeta_{\mathrm{o}}$ in peak and off-peak periods, respectively.

A key issue for the industry in the 1950s was whether the efficiency losses of average cost pricing were greater than the costs of running two electrical circuits and two meters in every household connected to the grid to facilitate such a policy - and evidently, it was not. Tariff experiments occurred in the late-1940s and 1950s which tried to overcome the inherent limitations of mechanical meters, such as inclining block and seasonal tariffs, the latter otherwise known as a Clow Differential Tariff. ${ }^{10}$ With meter readings undertaken four times per annum, the Clow Differential involved a higher tariff rate in the peak winter billing period, with the other three quarterly bills charged at a slight discount. But as Houthakker (1951, pp.5-6) noted at the time:

....seasonal [or inclining block] tariffs are a very crude method for limiting peak demand, as demand approaches its maximum only within short periods of the day, and these are precisely the periods when the relatively inelastic lighting component is important. Space heating, which has a special responsibility for the present peaks on cold mornings, is probably more sensitive to price changes than lighting but the elasticity varies with the time of day, and may be small on such mornings. Consumers will naturally economise at the times least convenient to them, and these are likely to be off-peak periods when no reduction of demand is required... More promising is the time-of-day tariff with a high unit rate for consumption during peak hours and a low rate for off-peak consumption...

Clearly, the appliance stock within modern Australian households differs considerably from postwar Britain. But by substituting the term "space heating" with "space cooling" and "morning" with "afternoon", Houthakker's comments from 1951 remain especially relevant for the NEM in 2012. A recent survey by the NSW energy regulator found that average household consumption in that state had declined by $5 \%$ over the five years to 2010 following a series of (average cost) tariff increases, but aggregate peak demand had increased by $10 \%$, from 13,200MW to $14,580 \mathrm{MW}$. In Queensland, average annual household energy demand has not moved materially since the late-1990s, but the number of households has increased by $34 \%$ while peak load had risen by 104\% (Simshauser et al, 2011a).

To illustrate the problem more specifically at the household level, Simshauser and Laochumnanvanit (2011) analysed 3000 residential customers in Sydney who had a new digital or "smart" meter, which records half-hourly load data. The granularity of this data allowed an examination of the 'peakiness' of household demand. 52.5 million meter readings from the 3000 customers for 2010 were condensed into two household load curves, which have been reproduced in Figure 3, the first being average daily demand, and the second being demand on a 'critical event day' where temperatures reached $40^{\circ} \mathrm{C} .^{11}$ On this critical event, household peak demand is up by $90 \%$ compared to average, driven by air-conditioners.

\footnotetext{
${ }^{9}$ It is worth noting that cycling power plant to meet volatile swings in electricity load comes at considerable long-run costs, costs that would not normally be captured or represented in a static or even dynamic short-run analysis.

${ }^{10}$ The tariffs were named after Sir Andrew Clow, the Chairman of the 1948 committee inquiry into "The electricity peak load problem in relation to non-industrial consumers".

${ }^{11}$ The households in Figure 2 consume an average of about 6.7MWh per annum (below the regional average of about 7.5MWh).

Nonetheless, it is the shape of the load curve that is of relevance to our analysis.
} 
Figure 3: Daily average demand vs. critical event demand from 3000 households

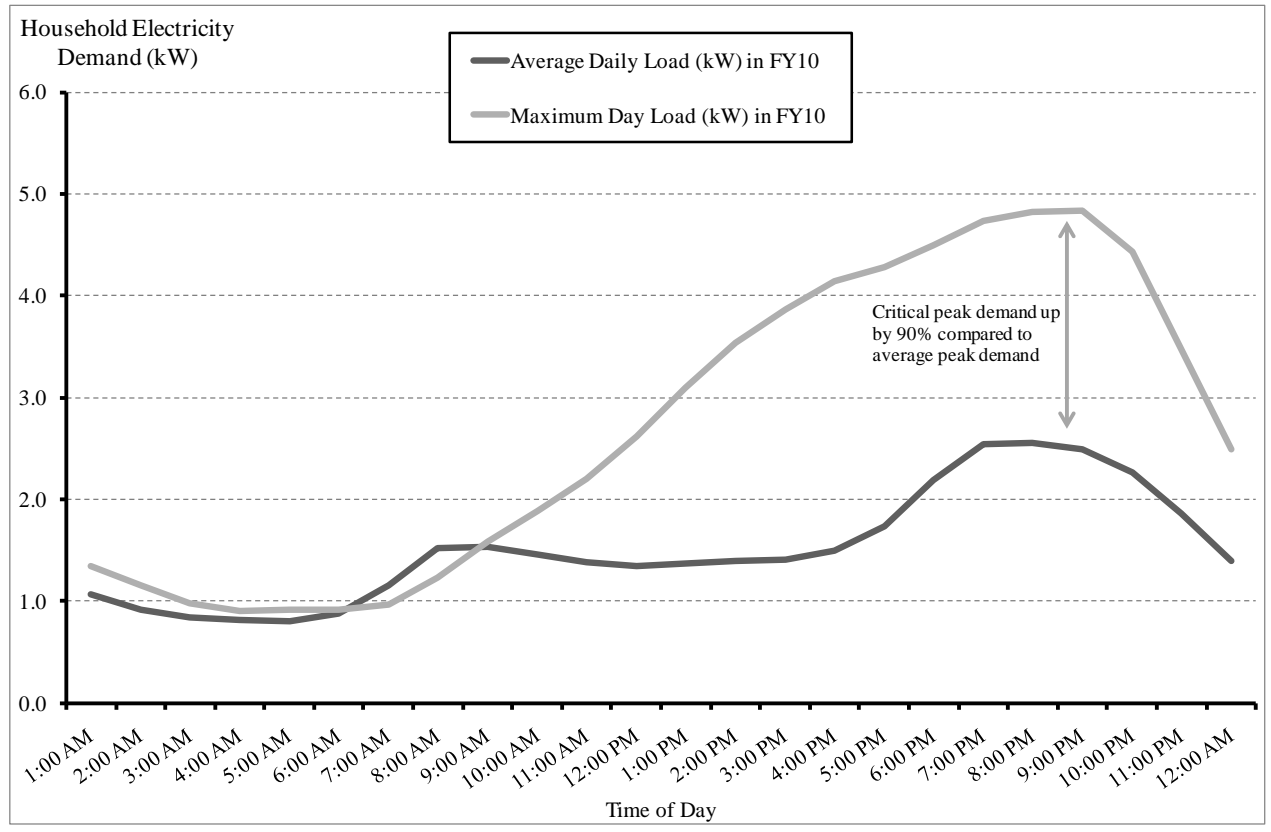

Source: Simshauser \& Laochumnanvanit (2011).

Electricity cannot be stored, and therefore there is no inventory from which to draw upon during peak periods, and unlike time-delays with transport congestion, electricity congestion can only be solved through blackouts, which is politically unacceptable. As a result, network infrastructure and generating plant capacity must expand to meet projected instantaneous peak demand (plus a margin for forecast errors and plant outages). The capital cost of doing so is non-trivial - more than $\$ 900$ million of capital has been invested in the distribution network in southeast Queensland and is used for just $3 \frac{1}{2}$ days per annum, albeit not contiguous days (SSC, 2010). To put this into context, the total capital stock of the southeast Queensland grid is $\$ 8$ billion, and thus $12.5 \%$ of the network is provided for use on $3 \frac{1}{2}$ days per annum. Yet for network companies to stay in business, investment costs must be recovered and with most households equipped with mechanical meters, this is done via average cost tariffs.

This raises a rather obvious issue for electricity consumers going forward. Peak demand is rising rapidly, causing more investment. Average cost tariffs are rising to recover the cost. While there is evidence to suggest annual consumption is moderating in response, peak demand is not for the reasons outlined above per Houthakker (1951, pp.5-6). As peak demand keeps rising, new plant capacity must be built to keep the power grid stable. The cost of this capacity must then be recovered, leading to yet further price increases. In short, increasing average cost tariffs is not dealing to the 'moment of scarcity'. Average cost tariffs are evidently substantially below the available consumer surplus on critical event days. As US energy economist Ahmad Faruqui (2010a, p5) recently noted, if prices throughout an economy were based on the average cost tariff principles used in the electricity industry, the entire economy would "be characterized by excess capacity and poor load factor, because prices would no longer be used to spread out periods of intense demand, and this alternative reality would be a world of higher prices."

The cost of deteriorating load factors can be quantified by reference to southeast Queensland electricity demand, a suitably representative NEM sub-region representing about $15 \%$ of total load. In Simshauser et al. (2011a, 2011b), a series of forecast prices for the entire electricity supply chain was provided for the future year 2015. We have reproduced the Queensland 'high 
gas' scenario in Figure 3, represented by the left-hand bar. ${ }^{12}$ Given a forecast load factor of $38.5 \%$ for Queensland households, this resulted in a tariff of $\$ 276 / \mathrm{MWh}^{13}$ and at $7.5 \mathrm{MWh}$ of consumption, a household bill of $\$ 2,066$ per annum. We have produced a second scenario where the load factor is assumed to increase by 11.5 percentage points, which as we will see later, requires a concerted effort. ${ }^{14}$

Figure 4: Queensland residential electricity bill in FY15 - low vs. high load factor

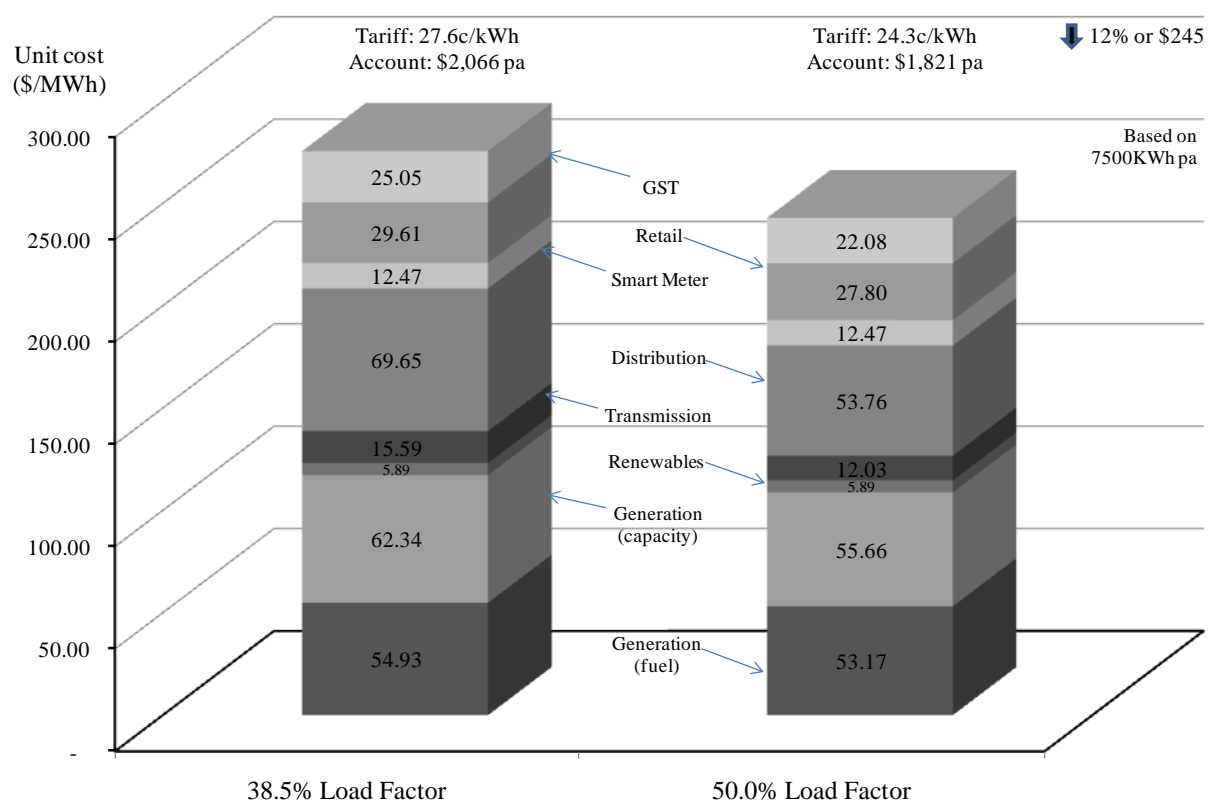

In order to generate this load factor scenario, we used the NEMESYS Model to determine generation fuel and capacity costs. NEMESYS is a dynamic, partial equilibrium model of the power system with half-hourly resolution and price formation based on a uniform, first price auction consistent with the NEM design. The NEMESYS model assumes perfect competition and essentially free entry to install any combination of capacity that satisfies differentiable equilibrium conditions. The lumpiness of new capacity is a constraint; firms may chose either 300MW CCGT base load plant or a 150MW OCGT plant based on conventional 'E Frame' gas turbine technology; a technology widely available from the main plant manufacturers. The NEMESYS model specifications have been documented in Simshauser (2008) and therefore we do not propose to reproduce them here.

The comparative scenario costs for generation fuel and capacity are clearly illustrated by the bottom two blocks in the Figure 4 'cost stack'. The higher 50\% load factor scenario led to a change in the plant stock by comparison to the $38.5 \%$ scenario. While not evident in Figure 3, base plant was increased and peaking plant reduced in response. This lead to a reduction in unit fuel costs, from $\$ 54.93$ to $\$ 53.17 / \mathrm{MWh}$ due to the higher combustion efficiency levels of base plant, and although there was a higher sunk capital cost arising from more base plant, the costs were spread across greater units of output, thereby reducing capacity costs from $\$ 62.34$ to $\$ 55.66 / \mathrm{MWh}$.

Transmission and distribution charges also decline due to enhanced loading of the power system. Holding the relevant revenue caps constant, unit transmission costs reduced from $\$ 15.59$ to

\footnotetext{
${ }^{12}$ In this scenario, gas prices were assumed to rise to a 'netback price' of $\$ 6.75 / \mathrm{GJ}$ compared to a domestic gas extraction cost plus margin of $\$ 3.60 / \mathrm{GJ}$.

${ }^{13} \$ 276 / \mathrm{MWh}$ is equal to $27.6 \mathrm{c} / \mathrm{kWh}$

${ }^{14}$ We opted to hold peak demand constant for ease of modelling. While doing so exaggerates energy consumed, it has the benefit of capturing the gains in network charges whilst eliminating the requirement to revise future network capital expenditure.
} 
\$12.03/MWh, and distribution from $\$ 69.65$ to $\$ 53.76 / \mathrm{MWh}$. Retail costs and GST also decline in-line with revised costs. All-in-all, this scenario, while highly stylized, demonstrates that gains from a flatter load curve are substantial; $-\$ 32.67 / \mathrm{MWh}$ or $-12 \%$. esaa (2010) data indicates there are 7.6 million households in Queensland, NSW, Victoria and South Australia, with the fourState average consumption being 6.7MWh pa. If a $\$ 32.67 / \mathrm{MWh}$ reduction was achieved in all four regions, this would equate to avoided costs of $\$ 1.7$ billion per annum in the household sector alone.

\section{Dominant thought on energy demand: virtually price inelastic?}

Until the mid-2000s, 'dominant thought' on household electricity demand was that it was highly price-inelastic. Prior to 2007, tariff increases in Australia had been met with virtually no sustained response from households. As a result, dominant thought is probably not without foundation given the essential service characteristic of electricity. As Rochlin (2009, p.15) observed:

...The obligation to serve, the lack of retail price signals reflecting the variable cost of production, the inability [of households] to respond to that price signal, and the lack of exclusion have created a truly unique economic aspect of electricity: the false belief that customers would not respond to price signals. The desire for relatively stable retail prices, the high cost of metering and an assumption that consumers must have electricity have resulted in a complete failure to move price variability to the retail level...

Demand response and energy efficiency, long argued as the low hanging fruit in the context of energy market reform, has been the perennial under-performer in deregulated markets globally. Quite simply, demand-side participation over the past 12 years since industry deregulation in the NEM has been trivial. The fact that residential demand management has featured so little can be attributed to the muting of peak price signals as illustrated in Figure 2, especially on critical event days. To compound matters further, the absolute cost of electricity in Australia has until recently declined in real terms as highlighted in Figure 1. This made it difficult to engage customers in any meaningful way. A consumer survey undertaken by Queensland power company Stanwell Corporation in the late 1990s found the electricity account to be the second most boring (i.e. least interesting) item in household budgets. Only council property rates received less attention. The IEA (2005) noted that despite more than 30 years of market interventions in response to energy price shocks, regulators and policy makers know surprisingly little about the consequences of intervention or the price elasticity of demand.

But an historical view of electricity demand is not a helpful starting point for discussions on forward policy settings in light of changed economic circumstances around the rapidly rising price of electricity, changed attitudes towards climate change, and technological advances including smart meters. It is un-contentious to suggest that the future cost of electricity will exceed credible forecasts of household income growth. This may therefore provide the conditions necessary to engage households more actively in demand response.

Faruqui and Sergici (2010) noted that the first wave of household demand response experiments can be traced back to the late-1970 and early-1980s by the US Federal Energy Administration. Data from the top five experiments were analysed by the US Electric Power Research Institute, and the results were conclusive; customers responded to time-varying prices by shifting loads into off-peaks, and results were consistent from around the country once weather conditions and the appliance stock were held constant. Demand response was greatest in warmer climates and in allelectric homes.

A second wave of experiments is now emerging, and this growing body of evidence is pointing to the capacity and willingness of households to alter demand patterns in response to pricing 
structures, technology or both. A study by Reiss and White (2008), while not intended as an analysis of the price elasticity of demand, provides insight on energy consumption under extreme system conditions. Their analysis took weather-adjusted electricity consumption and billing data for 70,000 households in San Diego over a 5-year period spanning either side of the Californian energy crisis of 2000. The study had the benefit of four distinct 'period events':

1. Stable Period: prior to the energy crisis, residential tariffs were set at US $\$ 110 / \mathrm{MWh}$. The 70,000 households consumed 6.1MWh pa on average (remarkably similar to East Coast Australian average retail prices and quantities at $\mathrm{A} \$ 110$ and $6.6 \mathrm{MWh}$ at that time).

2. Price Shock Period: the Californian energy crisis led to sharp increases in residential tariffs as wholesale electricity prices were 'passed-through' to customers. Tariffs were raised to US $\$ 230 / \mathrm{MWh}$. This represented a genuine price-shock because customers received their bills with a 3-month lag and without any real warning. Demand response over the ensuing 60-day period during the 2000 summer was marked; average household consumption declined by $13 \%$.

3. Price Suppression Period: due to public outrage, tariffs were re-set artificially below cost at US $\$ 135 / \mathrm{MWh}$ by the Californian Legislature. Electricity demand rebounded $8 \%$. The fact that demand did not rebound completely tends to indicate that there was a change in the appliance stock, dwelling improvements, or persistent changes in utilisation decisions.

4. Public Education Period: following the rebound in demand, a public campaign to reduce energy consumption was initiated at a cost of US\$65 million, on advertising in television, radio, newspapers, billboards and public schools. Government officials also made dramatic television appeals. It was highly effective with demand reducing by $7 \%$.

Importantly, Reiss and White (2008) found that approximately $40 \%$ of households were completely price inelastic despite tariff increases, and generally consumed $2.5 \mathrm{MWh}$ pa or less (the implication being that $2.5 \mathrm{MWh}$ is subsistence consumption), a finding that we will make use of later in this article. On the other hand, approximately $33 \%$ of households reduced electricity demand by $20 \%$ or more. A substantial share of the decline in aggregate consumption following the price shock came from a minority of households who reduced their demand dramatically, presumably at considerable inconvenience.

In the NEM, the size of the equivalent opportunity is significant. Figure 5 represents an analysis of 1,000 randomly selected customers in Victoria who were equipped with smart meters for the entire 2010 period. $^{15}$ It shows that fully $65 \%$ of households were high users of energy in peak periods (i.e. the top three boxes in Figure 5). Conversely, those with low peak consumption, who might be price inelastic, accounted for only $17.1 \%$ of our sample (i.e. the bottom three boxes in Figure 5).

15 About 2.8 million digital meters are being rolled out between 2010-2013 in Victoria. 
Figure 5: Distribution of household power consumption by peak and off-peak

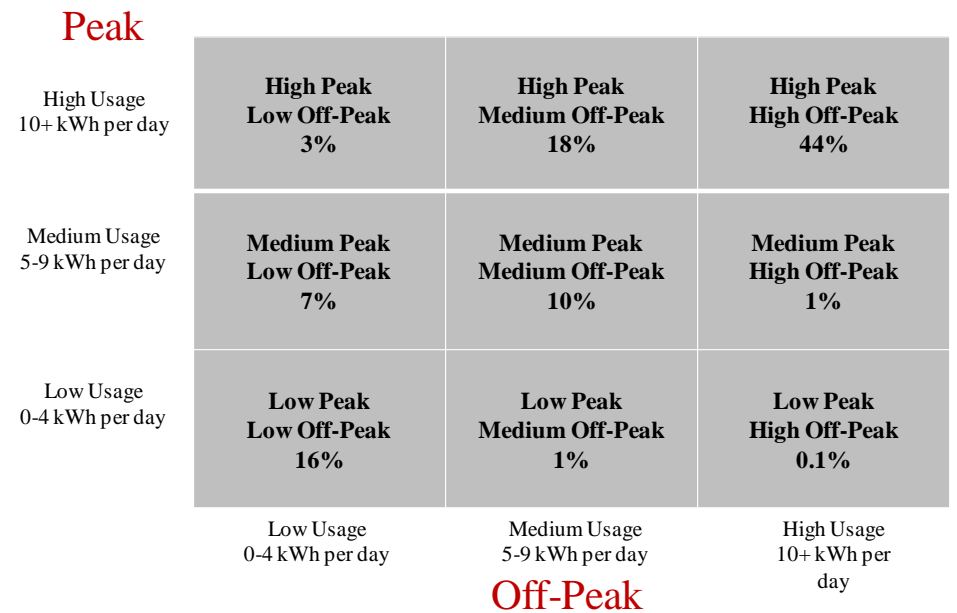

\section{On dynamic pricing}

So how can demand response be mobilised? Faruqui, Hledik and Sergici (2009) explained the appropriate template by reference to a pricing pilot in California during 2004 and 2005. The pilot was conducted in households equipped with smart meters. Consumers faced a peak price from $2 \mathrm{pm}-7 \mathrm{pm}$ on weekdays with all other times set at an 'off-peak' or base rate. Additionally, some houses were exposed to super peak events, in which a Critical Peak Price was applied. Super peak events could be called 24 hours in advance and a Critical Peak Price would be declared, which was set at multiples of the off-peak price. This describes the fundamental nature of dynamic pricing. An average cost tariff is replaced with a peak price, an off-peak price and a limited number of dynamic Critical Peak Price events, which can be called on up to 12 very hot, very cold, or supply-constrained days per annum with 24 hours notice. Dynamic pricing should not be confused with 'Real Time Pricing' in which the spot electricity price is directly passedthrough to the (unsuspecting) consumer. The Californian dynamic pricing trial was remarkably successful:

- Households on a conventional time-of-use peak/off-peak tariff structure reduced their peak demand by $5 \%$ on average; and

- Households on the time-of-use and Critical Peak Price structure reduced peak demand on critical event days by $13 \%$ on average.

The Californian pricing pilot outlined above is one of many examples. The quintessential applied economic analysis of dynamic pricing and its effectiveness is contained in Faruqui (2010b), where 70 pricing pilots from North America, Europe and Australia were analysed for their reduction in peak demand. We have reproduced the results from Faruqui (2010b) in Figure $6 .{ }^{16}$

\footnotetext{
${ }^{16}$ We are grateful to Dr Ahmad Faruqui from the Brattle Group, San Francisco, for supplying us with the underlying data.
} 
Figure 6: Peak demands reduction arising from various dynamic pricing pilots

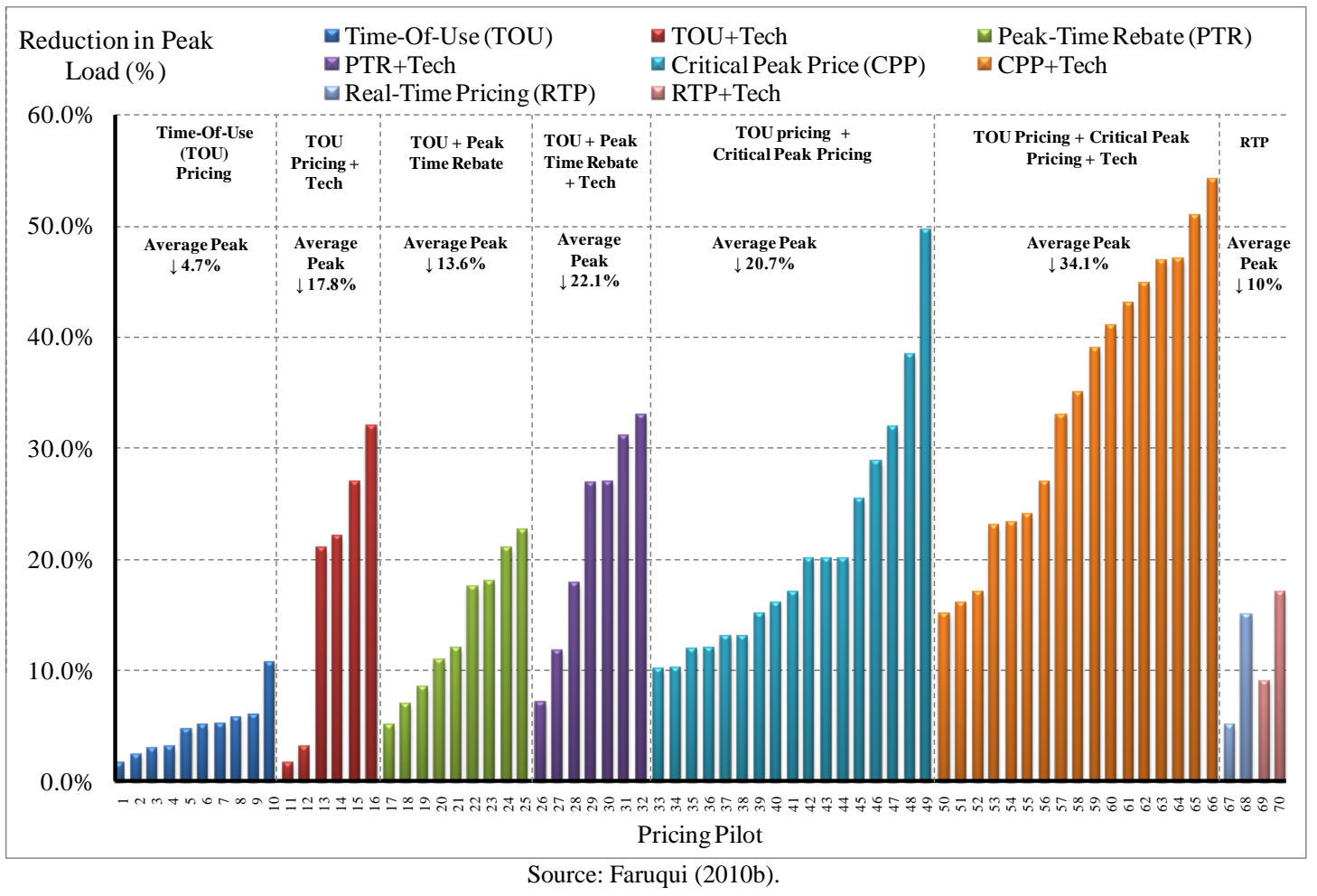

Pricing pilots reveal that the mere shift from average to time-of-use tariffs reduces peak demand by $4.7 \%$ on average, although to be sure some trials elicited a response as low as $2 \%$. Where technology is added to households to automate demand response, reductions averaged $17.8 \%$ and spanned a range of 2-32\%. Technologies include cycling switchers and Programmable Communicating Thermostats which enable appliances such as air-conditioning units to be throttled back, 'kill switches' which turn-off all appliances on stand-by mode, smart whitegoods which schedule their load by time, In-Home Displays and so on.

In the Peak-Time Rebate trials, consumers were rewarded for reducing demand below their average levels and in turn received a rebate on their bills. In these trials, peak demand was reduced by an average of $13.6 \%$ and spanned a range of 5-23\%. Where technology was added to automate demand response, the average reduction was $22.1 \%$.

But Critical Peak Pricing trials seem to hold the most promise, and have therefore experienced the greatest number of pilots. As Figure 6 illustrates, Critical Peak Pricing pilots have averaged a $20.7 \%$ reduction in peak demand at the household level, with results spanning 10-50\%. Technology driven demand response led to a surprisingly large $34.1 \%$ reduction in peak demand.

Real-Time Pricing trials have been least popular, no doubt due to the material uncertainty such a move would place on household budgets, not least the substantive risk such a move would place on system security given that a portfolio of customers is required to facilitate the financing of new generating equipment (Simshauser, 2010). Nonetheless, such trials have been initiated and generated load reductions of $5-15 \%$.

Clearly, demand response will vary in-line with the change in price levels, and the amount of education customers receive. Faruqui and Palmer (2012, p.5) compiled the demand response and differential tariff data from 60 pilots, with and without technology. Figure 7 reproduces the 'without technology' data set, for which they noted that: 
The magnitude of customer response varies with the price incentive - the higher the incentive, the greater the demand response. Multiple studies have observed and estimated the price elasticity's of participants. Baltimore Gas and Electric's pilot revealed substitution elasticity between peak and off-peak hours of -0.096 and -0.12 in 2008 and 2009, respectively. Connecticut Light \& Power's 2009 pilot showed substitution elasticity's of -0.08 for the Critical Peak Price rates and -0.052 for the PeakTime Rebate rates. Customers placed on the Critical Peak Price rate in the California State-wide Pricing Program pilot exhibited a substitution elasticity of -0.076, and customers in the Consumers Energy pilot showed -0.107 as their substitution elasticity. In each case, for a given elasticity of substitution, the demand response tended to increase with a higher peak-to-off-peak ratio, but at a decreasing rate...

Figure 7: Arc of price responsiveness

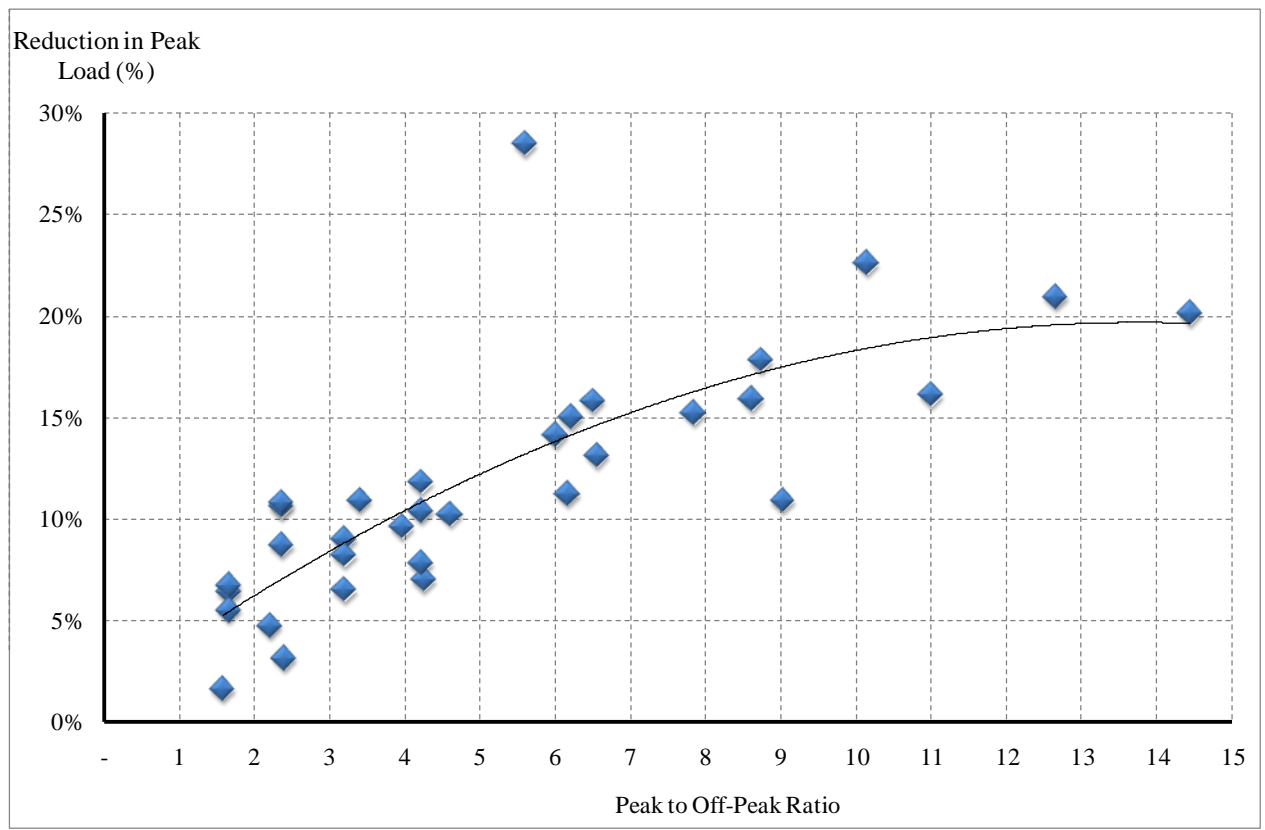

Source: The Brattle Group, Faruqui and Palmer (2011).

In addition to the substitution or 'load shifting' effect, inherent in the results from Figure 6 and 7 are absolute reductions in demand, known as the energy conservation effect. Lewis (2010) provided a summary of average results from pricing pilots, which we have reproduced in Figure 8. ${ }^{17}$ Figure 8 notes that consumer feedback, education and load control devices result in the highest conservation effect, whereas pricing, while highly effective in reducing peak demand, tends to result in more load shifting than conservation.

${ }^{17}$ Our thanks to Dr Philip Lewis from VaasaETT for providing us with the data. 
Figure 8: Drivers of energy conservation effects

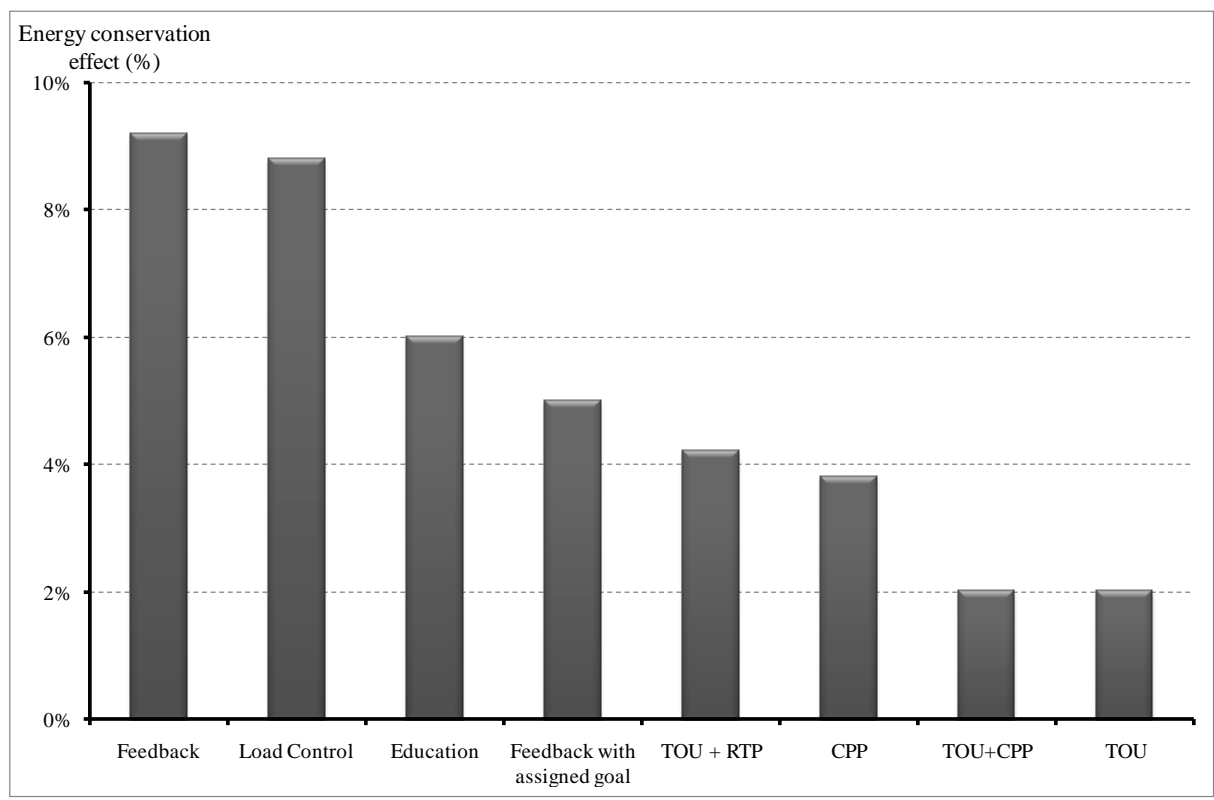

Source: Lewis (2010)

\section{Results: the impact of Dynamic Pricing on household electricity bills}

In preceding sections, we have set out a proximate case for dynamic pricing on the grounds of reductions in peak demand. In this section, we analyse the distributional effects of such reforms. In doing so, we have made use of our 52.5 million meter data reads from the 3000 Sydney households outlined in Section 3. Using a computable model, we have simulated household bills under three conditions (a) a base case involving existing average cost tariff structures; (b) a timeof-use tariff with a peak and an off-peak tariff, and (c) time-of-use peak and off-peak tariffs + Critical Peak Price structure.

Specifically, our base case assumes a conventional two-part tariff structure with a fixed tariff of 60 cents per day and 'consumption' tariff of $\$ 200 / \mathrm{MWh}$. Our alternate cases combine the twopart tariff structure with the time-of-use structures, retaining the fixed tariff of 60 cents per day, but with the flat consumption tariff replaced with a peak tariff of \$298/MWh (7am-11pm, MonFri) and an off-peak tariff of $\$ 87.50 / \mathrm{MWh}$. In the time-of-use + Critical Peak Price structure, the Critical Peak Price has been set to $\$ 613 / \mathrm{MWh}$ (i.e. 7 times the off-peak tariff) with the peak tariff reduced from $\$ 298 / \mathrm{MWh}$ to $\$ 278$ and the off-peak tariff held constant at $\$ 87.50 / \mathrm{MWh}$.

In our first round of simulations, we assume zero demand response by households regardless of structure - which in the very short run is a realistic assumption given a three month lag in billing, at least in the absence of a substantial upfront education campaign. By initially assuming no demand response, we are able to identify the portion of households which would be left betteroff, worse-off, or indifferent by changing tariff designs. Put another way, holding demand constant enables us to identify the portion of households that are currently overcharged, and those that are being subsidised through average cost pricing given the unique load shapes of households. The results of this first round of simulations are displayed in the Figure 9 "propeller curves", with the time-of-use scenarios benchmarked against the average cost tariff case. 
Figure 9: Dynamic pricing distribution effects - no demand response

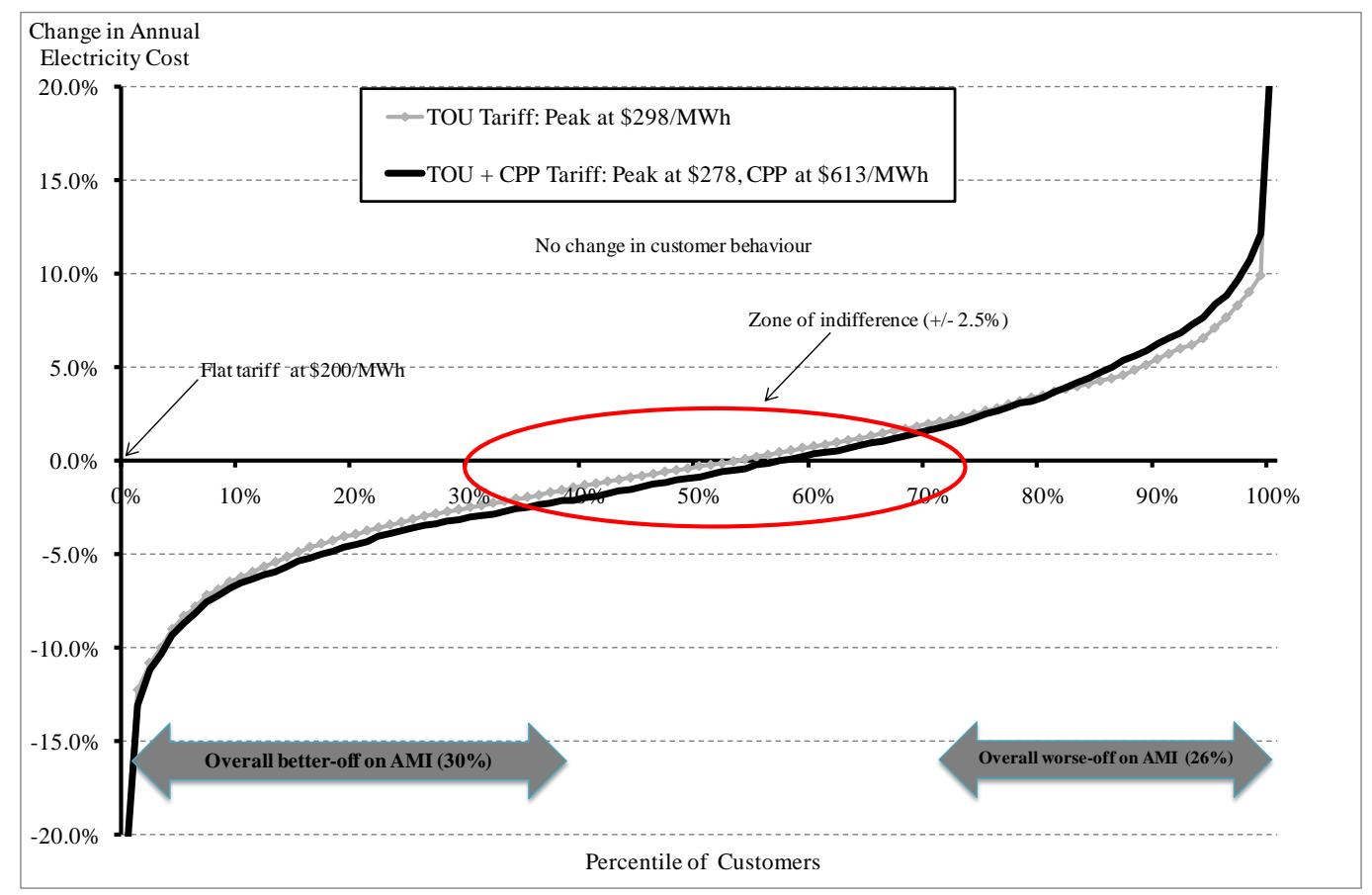

The propeller curves in Figure 9 clearly illustrate the distributional impacts on households. Those worse-off on the propeller curves are the proportion of consumers registering non-negative values (i.e. with the y-axis measuring the percentage increase in their electricity bill as a result of the change). We identify a zone of relative indifference, in which we take to be an impact of $+/-2.5 \%$ on annual electricity costs when compared to the average cost tariff of $\$ 200 / \mathrm{MWh}$. Households which are unambiguously better-off account for $30 \%$ of the sample, while those clearly worse off account for $26 \%$ of the sample. Removing the zone of relative indifference, $52 \%$ of households are strictly better off, and $48 \%$ worse off; not an entirely surprising result. Crucially, all three cases are "revenue equivalent", that is, industry profits have been levelised in a static sense. We also isolated customers that were flagged as 'pensioners' (about $12 \%$ of the sample) to assess the impact of dynamic pricing on this particular customer cohort. $21 \%$ were found to be unambiguously better off, and those clearly worse off accounted for $44 \%$ of the customer subset. The results of this analysis are provided in Appendix I.

The reduction in efficiency losses outlined in Figure 2 arising from time-of-use pricing have been analysed in our second round of simulations in which demand response has been applied, holding the household technology stock constant. Figures 6, 7 and 8 from Section 5 illustrated the effects of cross-price or substitution elasticity of demand (i.e. load shifting from peak to off-peak), and own-price elasticity of demand (i.e. the conservation effect) from a shift to dynamic pricing. For the purposes of our subsequent modelling, we assume a cross-price elasticity of -0.10 and an own price elasticity of demand of -0.05 in line with the findings of Faruqui and Palmer (2012) and CRA (2005), respectively. We also assume households consuming less than 2.5MWh per annum are price inelastic in line with the findings of Reiss and White (2008). Our simulation results are illustrated in Figure 10. They reveal that $75 \%$ of consumers would be better-off under a time-ofuse rate, and $77 \%$ would be better-off under a Critical Peak Price structure. We also tested the effects on the pensioner cohort and found that $57 \%$ would be better-off under time-of-use pricing, up from $35 \%$ in the first round of simulations (see Appendix II for pensioner only results).

Above all, the consolidated household load factor improves by fully 9 percentage points under this scenario. 
Figure 10: Dynamic pricing distribution effects - with demand response

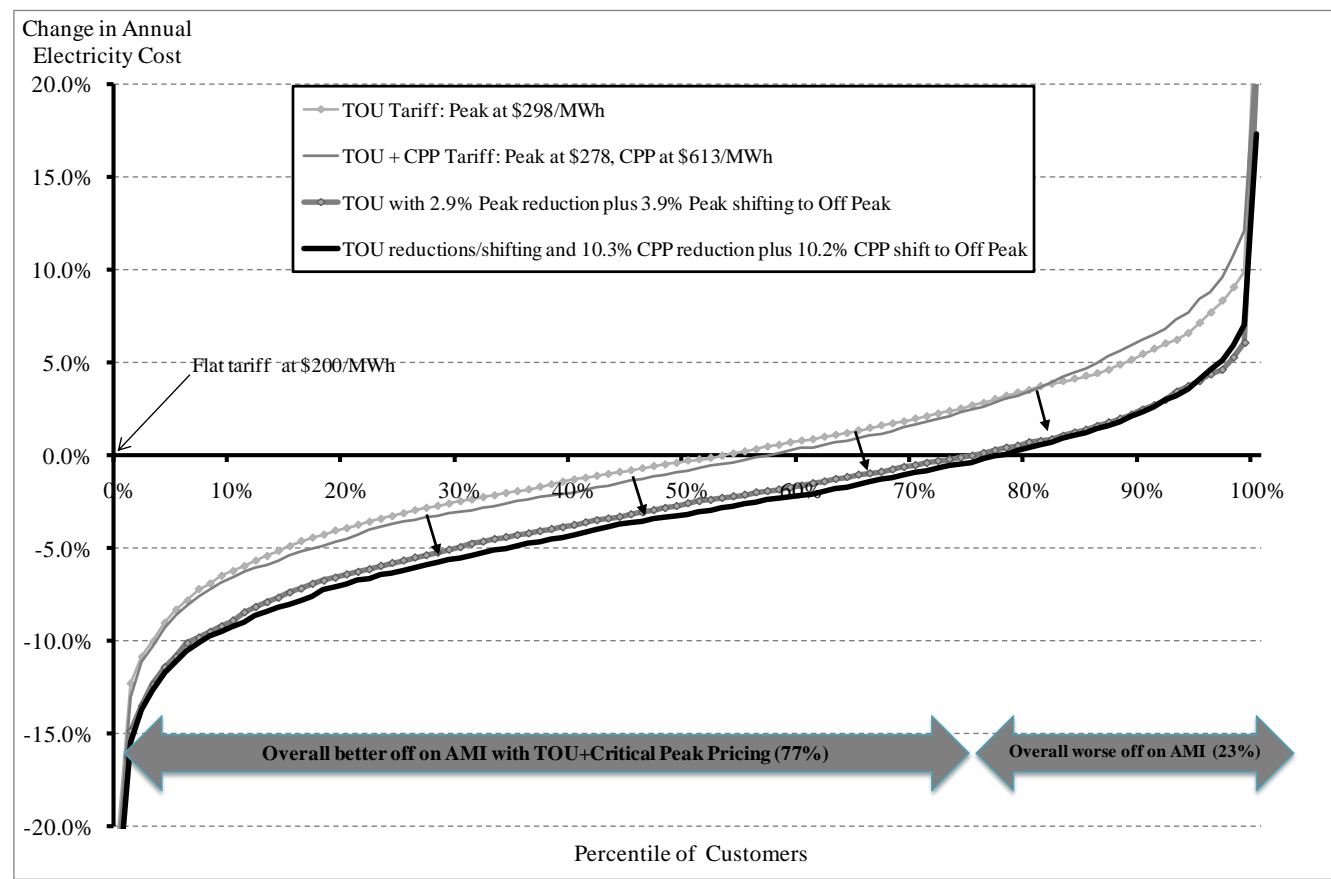

While these results are promising, demand response induced via dynamic pricing is unlikely to translate into immediate reductions in industry capital investment, and therefore immediate reductions in tariffs as Houthakker (1951) noted. Given energy security constraints faced by the industry, demand response must first be demonstrably sustainable. Additionally, demand response needs to be very carefully modelled because the benefits to the power system are highly unlikely to be linear, as Earle, Kahn and Macan (2009) demonstrate. Their analysis illustrated that demand response at a household level is likely to be subject to decreasing returns to scale. They argued that shifting consumption results in power system load curves acquiring a "fang" on critical event days - thereby creating new "shoulder peaks". We found similar results with our modelling of demand response, per Figure 11. The likely gains from demand response therefore need to be tempered, as opposed to extrapolated, in power system analysis.

Figure 11: Impact of demand response on critical event load curves

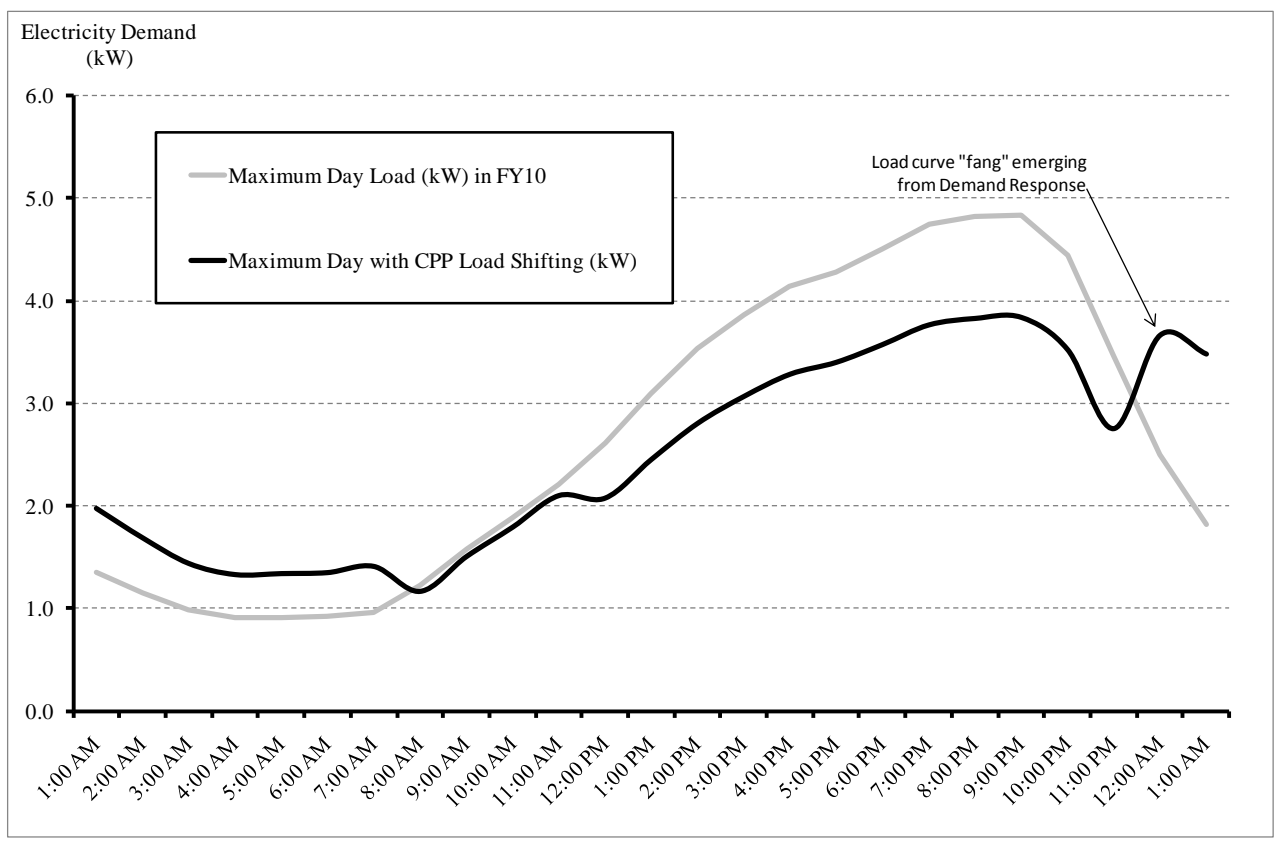




\section{Policy implementation - pacing and sequencing}

A shift to dynamic pricing is both a necessary and worthwhile reform. The cost-benefit of the smart meter rollout in Victoria has been well documented by Oakley Greenwood (2010), with a low case expected benefit of $\$ 1.8$ billion exceeding costs of $\$ 1.6$ billion. The low case expected benefits did not include any gains arising from a shift to dynamic pricing. The potential gains to power system utilization arising from dynamic pricing seem clear enough, yet the pace of reform in this arena has been grindingly slow. As Cornell University economist Robert Frank (2009, p.127-128) noted:

"If the benefits of congestion pricing are so compelling, why is it so rarely adopted? Although studies have shown, for example, that daily and seasonal variations in electric rates would substantially reduce the average consumer's utility bills, proposals to adopt such rate plans are typically rejected because of concerns about low-income users who may lack the flexibility to alter their consumption patterns. That such concerns often block economically efficient programs is one of the enduring mysteries of modern political economy. An economically efficient program is, by definition, one whose benefits exceed its cost. That means there must be ways of redistributing the gains so that every citizen, rich and poor, comes out ahead. Failure to adopt an efficient program thus raises the question of why we couldn't figure out how to accomplish the necessary transfers."

The logic of Frank (2009) is unambiguously correct, but the political economy of such a change to electricity tariffs in the NEM (especially at the time of writing) is difficult to overstate. Hanser (2010) also noted the while it is nearly certain that the increased cost of providing smart meters and usage information to consumers will be beneficial in the long run, the long run could be quite long. And, so while the arguments against dynamic pricing may not be especially compelling in theory, they are important in practice, and therefore warrant examination.

With the exception of Victoria, State Governments have so far been unwilling to deregulate prices despite the fact that the NEM boasts some of the most competitive retail supply markets in the world (Simshauser and Laochumnanvanit, 2011). And while State Governments are generally supportive of making time-of-use pricing optional to households, none are yet willing to allow it to be set as 'the default'. Alexander (2010) noted that moving residential customers en masse to dynamic pricing is capable of producing adverse consequences and a customer revolt. This is more than a theoretical possibility. A pilot in Seattle resulted in exactly that, largely as a consequence of the political economy of electricity prices as The Economist (2009 p.2) noted:

...Where variable rates were tried in Seattle a few years ago, most suburbanites liked the idea at first. They duly resisted turning on their dishwashers and so on until 9pm, the magic moment at which the local utility, Puget Sound Energy (PSE), started to charge less. But the mood quickly soured when it turned out that many households on the "timeof-use" rate plan actually paid more than ordinary ones. Consumers quit the programme in droves. In November 2002, only 18 months after it was introduced, PSE cancelled it with the backing of regulators...

CUAC (2010) observed that senior and concession consumers, who are mainly at home during the day, may struggle to pay peak rates for electricity. McGann and Moss (2010) identified two key segments of low-income consumers who will be worse-off with dynamic pricing. The first group is peaky households who are high users of energy because of unemployment, disability, or caring for young children or elderly relatives. The other group is peaky households with inelastic electricity use, that is, those unable to shift their usage due to the inability of appliances to be programmed to run in off-peaks. Alexander (2010) observed that low-income households invariably have a significantly lower level of price elasticity than high-income customers. Such 
concerns are legitimate as evident in Reiss and White (2008), and Felder's (2010) US data confirms the strong positive correlation between income and energy consumption. However, these concerns presume the absence of a package of policy measures to better achieve efficiency and equity objectives, such as simultaneously including rebates to hardship customers or exclusion from the program in the case of households using vital medical equipment.

Alexander (2010) noted that tariff pilot programs, such as those in Figure 6, are based on relatively small groups of volunteers who receive extensive education and 'hand holding' during a relatively short pilot. While this is true enough, it discounts the fact that all pricing pilots are controlled experiments with groups that are representative of the consumer base.

Brand (2010) noted that over the long run, the ability of customers to respond will be a function of the differential between peak and off-peak rates. But in the short run, steep increases in peak prices may cause bills to rise dramatically for some households unless the reasonable means to respond to scarcity pricing exists. A potentially large problem associated with the initial implementation of dynamic pricing is, therefore, 'bill shock', given the three monthly billing cycle. Recent history in the NEM has shown that unexpected non-trivial increases in electricity bills can lead to community outrage, and in turn, highly adverse media coverage. ${ }^{18}$ If adverse media coverage is sustained, it heightens the risk of a political response to policy settings. This however only underscores the importance of ensuring a package of policy measures is deployed, especially to households in genuine hardship.

Bunzl (2010, p.8-9) argued that to negotiate the politics of tariff policy, settings should be designed in light of Rawls' famous phrase, "from behind the veil of ignorance". That is, in selecting policy, I will not know whether I am rich or poor, renter or owner, and so on. And in doing so, "I would do well to decide with an eye on making the worst-case alternative the best of all possible worst-case scenarios; I ought to focus on being both poor and having a peakier load than average." With this in mind, he suggested inverted-block tariffs, which do not require the cost of metering changes, and appear to be an attractive alternative to dynamic pricing on the grounds of fairness.

However, Houthakker's (1951) analysis of Clow Differential tariffs identified why such thinking simply will not work - in the late 1940s British electricity consumers economised at times least convenient to them, that is, in off-peak periods, not the points of scarcity on critical event days. Australian consumers in the 2010 s are evidently no different - as we noted earlier, growth in peak demand is twice that of underlying energy demand. Worse still, if peak demand continues to rise on critical event days but underlying annual energy consumption falls through inclining block tariffs, primarily in off-peak periods, the industry is likely to experience an energy market death spiral (Severance, 2011). In an energy market death spiral, investment requirements continue at pace to meet critical peak events causing tariffs to rise, while reduced non-critical peak consumption reduces the available MWh to spread the industry's heavy fixed costs across, further inflaming tariff increases. ${ }^{19}$

\footnotetext{
${ }^{18}$ During 2011, a series of adverse newspaper articles appeared in the mainstream media on the east coast of Australia, which focused on the link between bill shock (i.e. rising tariff levels) and the costs of augmenting the distribution network. As Simshauser and Laochumnanvanit (2011) noted, in 2011 there were more than 5500 media articles on electricity prices in NSW and Queensland alone. Articles frequently focused on the "cost of living" rather than the peak load problem. The initial policy responses that emerged were focused on the regulatory process for setting monopoly network tariffs, with scant reference to the underlying source of the problem rising household peak demand. Consequently, the Australian Energy Regulator is now reviewing the tariff regulation framework, not the peak load problem. Although to be sure, the Australian Energy Market Commission is focused on demand response and the peak load problem.

${ }^{19}$ The grounds for shifting to dynamic pricing to meet environmental objectives is also contentious because of the dominance of load shifting, as opposed to energy conservation effects (Alexander, 2010; Brand, 2010). Brand (2010) noted in the case of the US, offpeak power is the primary domain of coal plant, whereas peaking plant tends to be lower emission technologies such as gas. These arguments are equally applicable to the NEM. However, dynamic pricing does not, in our opinion, need to deal directly to environmental objectives. In the NEM, this is better done through a separate suite of policies including renewable targets, carbon pricing and energy efficiency schemes. But the potential of such schemes are substantially muted through average cost pricing. For
} 
In our view, while the politics of shifting to dynamic pricing may be complex (at least initially), particularly given our findings in relation to the pensioner cohort illustrated in Appendix I and II, the counterfactual is also important. It is generally understood by consumer advocacy bodies in Australia that average cost tariffs lead to over-consumption in peak periods, and that peak demand is dominated by non-vulnerable households. All consumers are bearing the cost of power system augmentation as a result. Since dynamic pricing deals to these issues, it meets a "fairness criteria". But as Stiglitz (2002) noted in the case of macro and microeconomic reforms enforced on countries by the International Monetary Fund, incorrect pacing and sequencing can do much more damage than good. To that end, Hogan (2010) noted four preconditions for policy implementation regarding pacing and sequencing (1) the provision of accurate information on rate design and usage must be readily available, (2) customer education prior to implementation, (3) demand elasticity should be non-zero, and (4) the expected benefits of the program should exceed implementation costs. One critical observation that Hogan (2010) made is that the choice of the default tariff is important and that smart meters are not free, and their cost structure differs importantly from the cost of providing energy.

\section{Concluding remarks}

The transformation from average cost to dynamic time-of-use tariff structures needs to be strategically orchestrated by policymakers. An intensive consumer education program with substantial government input and resources is a prerequisite. Genuine commitment from politicians will be required. The energy industry must also take greater responsibility to ensure that households better understand the component costs of electricity, and the drivers of consumption in the household. As Honebein (2010, p.77-79) noted:

Smart meters can help customers save money. However, the road to achieving these benefits is a curvy one with numerous potholes along the way... Customer education is a process, not an event. Customers need some basic educational materials before the rate starts to point them in the right direction. Then as the program evolves, they need educational boosters along the way...

The ideal solution would be to utilise the tax and transfer systems available to governments so as to facilitate an appropriate package of policies, and specifically, financial compensation to vulnerable households. This would allow the widespread use of dynamic pricing as the default in the interests of an efficient allocation of resources nationally. In doing so, vulnerable households could face dynamic prices and choose to either hold their demand constant and fund this by the compensation received, or modify consumption and use compensation in other ways to lift their standard of living.

Crucially, a dynamic pricing program should not be initiated at the start of the peak summer period. This will minimise the incidence of "bill shock". If simultaneous compensation policies become suboptimal due to funding constraints, a dynamic pricing program could still be initiated but subject to a limited number of segment carve-outs, acknowledging that sending potentially 'punitive signals' to highly vulnerable households or consumers reliant on lifesaving medical equipment is clearly more than a theoretical one. Carve-outs may dilute participation rates, and therefore some of the potential gains. But electricity is considered an essential service, and the alternative may result in a head-on collision between voters and the media on one hand, and the energy sector on the other, with politicians in the middle. When this occurred in Seattle, the outcome was policy abandonment and is an important lesson.

example, smart meters and dynamic pricing could be matched to increase the penetration of renewables, and energy efficiency schemes become more economic to implement if an arbitrage exists between peak and off-peak prices. 
That $\$ 900 \mathrm{~m}$ of capital has been invested in the southeast Queensland grid, for use $3 \frac{1}{2}$ days per year, would incense any macroeconomist from a national resource allocation perspective. Capital allocated to the grid, and to generating equipment across the entire NEM for "momentary use" must surely be a vast multiple of this. The benefits associated with the alternate use of such scarce capital in our economy must be higher again. But to try and correct such adverse distortions into the future, all roads lead back to the critical importance of equipping households with a smart meter.

\section{References}

AEMC: Australian Energy Market Commission, 2011, "Strategic Priorities for Energy Market Development", AEMC Discussion Paper, Sydney.

Alexander, B. 2010, "Dynamic pricing? Not so fast! A residential consumer perspective", The Electricity Journal, 23(6): 39-49.

Boiteux, M. (1949), "La tarification des demandes en pointe: Application de la theorie de la vente au cout marginal", Revue Generale de l'Electricite, Translated by H. Izzard in Journal of Business, Boiteux, M. 1960, 'Peak load pricing', Journal of Business, 33(2): 157-80.

Brand, S. 2010, "Dynamic pricing for residential electric customers: a ratepayer advocate's perspective", The Electricity Journal, 23(6): 50-55.

Bunzl, M. 2010, "Is flat fair?", The Electricity Journal, 23(6): 8-12.

CRA: Charles River Associates. 2005, "Impact evaluation of the California Statewide Pricing PilotAppendices”, Charles River Associates Publication, Oakland California.

CUAC, 2010, "Consumers need clarity on smart meter roll out", CUAC Media Release, 23 March. Available at http://www.cuac.org.au/database-files/view-file/4162/. Accessed 5 November 2010.

Earle, R., Kahn, E. and Macan, E. 2009, "Measuring the capacity impacts of demand response", The Electricity Journal, 22(6): 47-57.

esaa: Energy Supply Association of Australia, 1994, 1996, 2005, 2010, ElectricityGas Australia, esaa publication, Melbourne.

The Economist, 2009, "Wiser wires", The Economist, $8^{\text {th }}$ October 2009.

Faruqui, A. 2010a, "Residential dynamic pricing and energy stamps", Regulation, Winter 2010-2011, pp 45.

Faruqui, A. 2010b, “The ethics of dynamic pricing”, The Electricity Journal, 23(6): 13-27.

Faruqui, A. 2011, "Michigan Speaks: Consumer Energy's Dynamic Pricing Experiment”, Presenation to CRRI Western Conference, Monterery, California, 16 June 2011.

Faruqui, A., Hledik, R. and Sergici, S. 2009, "Piloting the smart grid", The Electricity Journal, 22(7): 5569.

Faruqui, A. and Palmer, J. 2012, "Dynamic pricing of electricity and its discontents", Regulation, article inpress.

Faruqui, A. and Sergici, S. 2010, "Household response to dynamic pricing of electricity: a survey of 15 experiments", Journal of Regulatory Economics, 38(2): 194-225. 
Faruqui, A., Sergici, S. and Sharif, A. 2010, "The impact of informational feedback on energy consumption - a survey of the experimental evidence”, Energy, 35(4): 1598-1608.

Felder, F. 2010, "The practical equity implications of advanced metering infrastructure", The Electricity Journal, 23(6): 56-64.

Frank, R. 2009, The Return of the Economic Naturalist, Virgin Books, London.

Hanser, P. 2010, “On dynamic pricing: a clash of beliefs?”, The Electricity Journal, 23(6): 36-38.

Hogan. W. 2010, “Fairness and dynamic pricing: comments", The Electricity Journal, 23(6): 28-35.

Honebein, P. 2010, "We got a new digital meter. Our usage went up 123\%. Our bill went up 65\%." The Electricity Journal, 23(2): 76-82.

Houthakker, H. 1951, "Electricity tariffs in theory and practice”, The Economic Journal, 61(241): 1-25.

IEA: International Energy Agency, 2005, "Energy Policies of IEA Countries - Australia 2005 Review", IEA Publication, Paris. Available at http://www.iea.org/textbase/nppdf/free/2005/australia2005.pdf

Lewis, P. 2010, "Benefiting customers through smart meters: lessons from around the world", Conference Paper, Business Circle Smart Metering Event, Vienna, November 9-10, 2010.

McGann, M. and Moss, J. 2010, "Smart meters, smart justice? Energy, poverty and the smart meter rollout", The University of Melbourne, Melbourne. Available at http://www.socialjustice.unimelb.edu.au/Research/smart_meters_smart_justice.pdf

Oakley Greenwood, 2010, "Benefits and costs of the Victorian AMI program", Final Report to the Department of Primary Industries, Oakley Greenwood Publication, Melbourne.

Reiss, P. and White M. 2008, "What changes energy consumption? Prices and public pressure", RAND Journal of Economics, 39(3):636-663.

Rochlin, C. 2009, "The alchemy of demand response: turning demand into supply", The Electricity Journal, 22(9): 10-25.

Severance, C. 2011, "A practical, affordable (and least business risk) plan to achieve $80 \%$ clean electricity by 2035", The Electricity Journal, 24(6): 8-26.

Simshauser, P. 2010, "Vertical integration, credit ratings and retail prices settings in energy-only markets: navigating the Resource Adequacy problem", Energy Policy, 38(11): 7427-7441.

Simshauser, P. and Laochumnanvanit, K. 2011, "The price-suppression domino effect and the political economy of regulating retail electricity prices in a rising cost environment", AGL Working Paper No. 21, Sydney. Available at www.aglblog.com.au

Simshauser, P., Nelson, T. and Doan, T. 2011a, "The Boomerang Paradox, Part I: how a nation's wealth is creating fuel poverty", The Electricity Journal, 24(1): 72-91.

Simshauser, P., Nelson, T. and Doan, T. 2011b, “The Boomerang Paradox, Part II: policy prescriptions for reducing fuel poverty in Australia", The Electricity Journal, 24(2): 63-75.

SSC: Smart State Council, 2010, An EnergySmart Plan: positioning Queensland for a diversified energy future 2010-2050, Queensland Government Publication, Brisbane.

Stiglitz, J. 2002, Globalisation and its discontents, Penguin Putnam Inc, New York. 
APPENDIX I - Dynamic pricing distribution effects - no demand response (pensioner cohort)

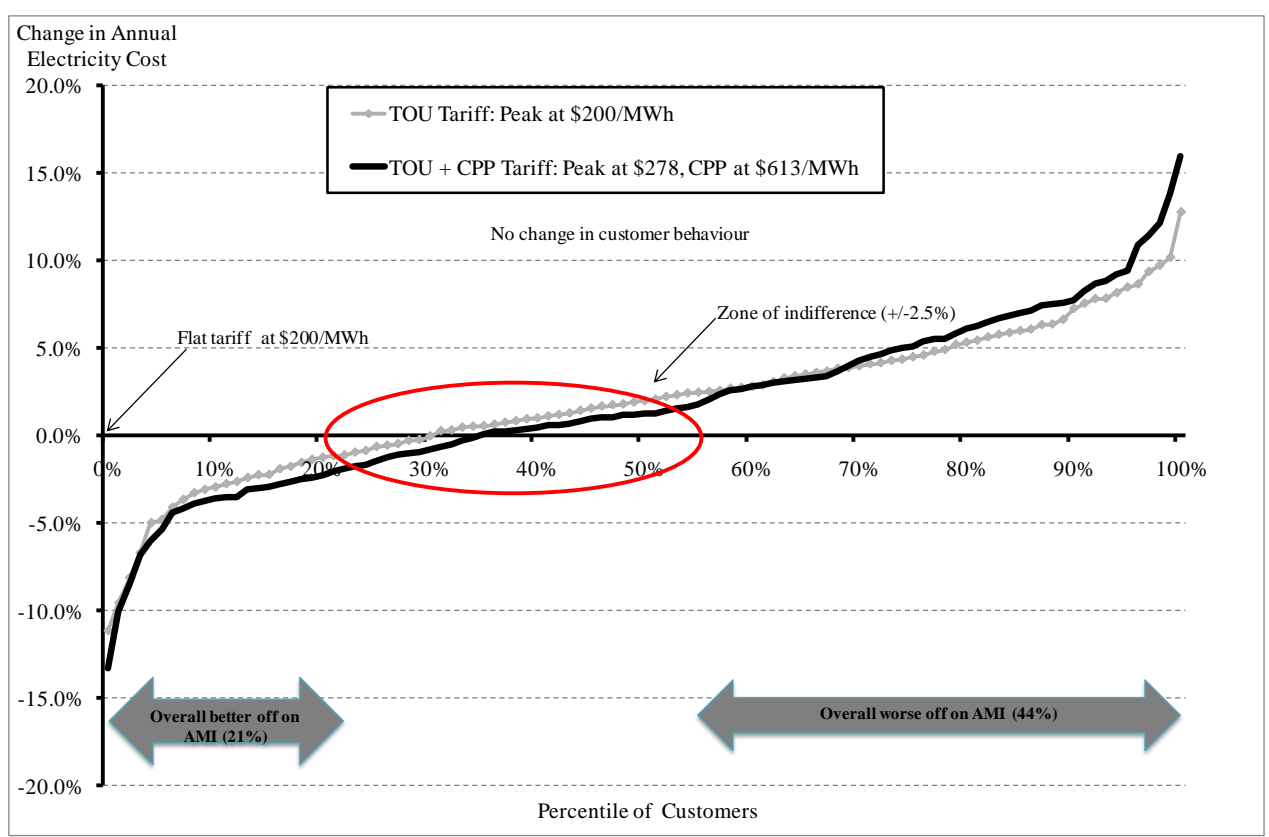

APPENDIX II - Dynamic pricing distribution effects - with demand response (pensioner cohort)

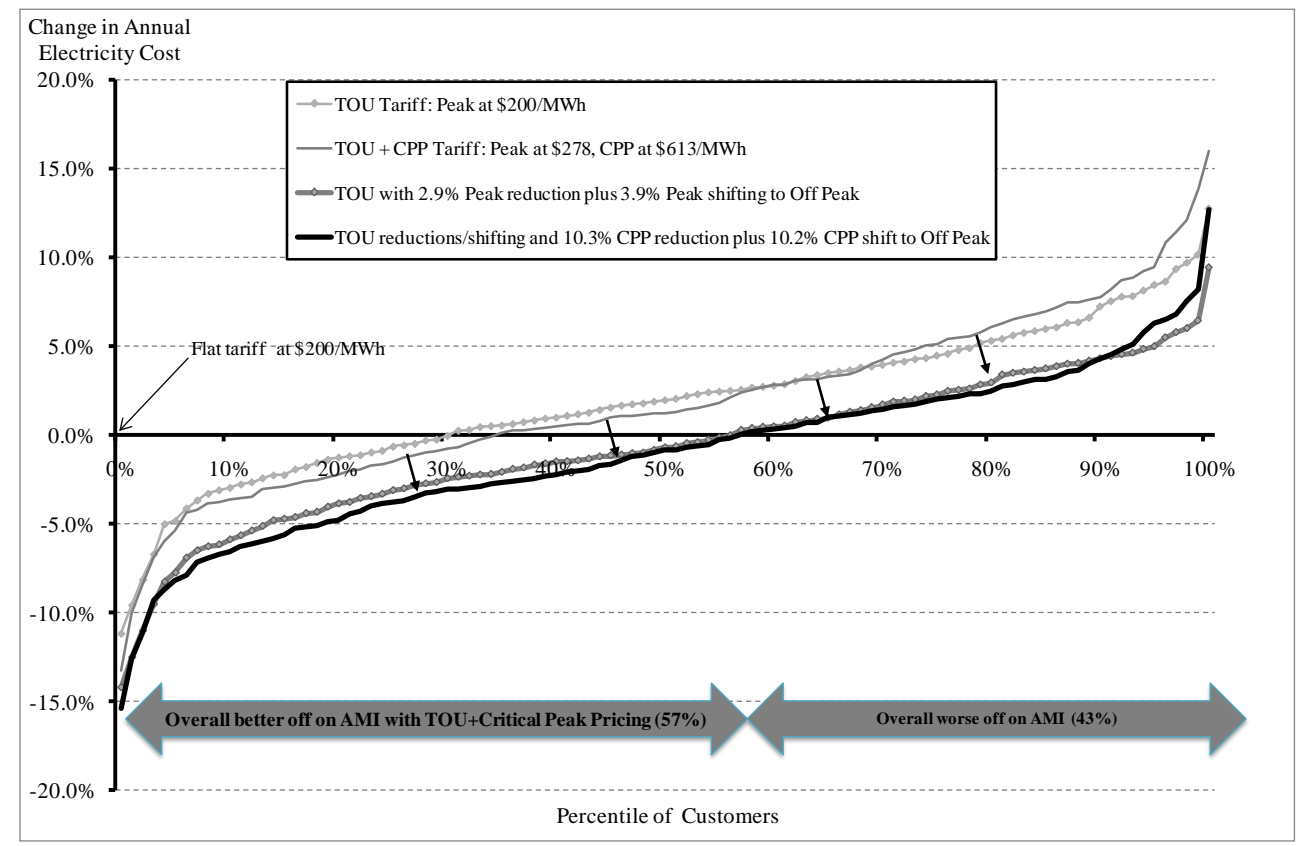

